\title{
A Comparative Study on Multi-goals of Farm Hotel Operators between China and Australia
}

\author{
Xiuhong Wang \\ Department of Tourism Management, Henan Vocational College of Agriculture, Zhongmu, Zhengzhou City, Henan Province, \\ China \\ wangyuming03@163.com
}

\begin{abstract}
Different social backgrounds and developmental stages in tourism industry resulted in disparities in multi-goals of farm hotel operators between China and Australia. The multi-goals of farm hotel operators were analyzed from such aspects as start-up goals, formal business goals and family-related goals. Finally, the underlining causes leading to these differences were explored from population characteristics, social systems, regional developmental level of economy, cultural diversity and understanding of rural areas.
\end{abstract}

Index Terms - farm hotels, operators, multi-goal, comparison

\section{Introduction}

Rural tourism, which originated in Europe in the mid-19th century [1], has become one of indispensable part of tourist industries in western countries [2]. In China, modern rural tourism originated only in the 1980s in Nongke village, Pixian county, Chengdu City of Sichuan [3]. The farm houses, which provided simple accommodation and travel services, was dubbed the unique Chinese epithet -farm stay. With sharp rise of domestic tourism demand and supporting policies from the state, rural tourism had undergone unprecedented development in the past 30 years [4]. To explore the different goals of farm hotel operators in China and western countries, farm hotels of Queensland State in Australia and Shanghai, Wuhan, and Chengdu in China were chosen. The comparative study on multi-goals of farm hotel operators in China and Australia was conducted from the aspects of start-up goals, formal business goals and family-related goals [5].

\section{Start-up Goals}

Shanghai, Wuhan and Chengdu represent China's eastern, central and western regions both in economic development stages and in rural tourism. The differences in the multidimensional goals of farm hotel operators between the above three cities in China and Australia are worthy of further research.

\section{A. Recessive Start-up Goals}

The common points of Chinese and Western recessive start-up goals are that "Social intercourse" and "lifestyle" rank in the first two places, and "self- reliance" ranks last. It means that the main start-up goals of Chinese and Australian rural tourism operators are to motivate social intercourse and pursue rural lifestyle. They care less about the goal of "self-reliance". These four recessive start-up goals, especially the goal "money", got more recognition from rural tourism operators in three Chinese cities than in Queensland of Australia. This means that Chinese rural tourism operators gave more recognition to these four recessive start-up goals. Furthermore,
Chinese rural tourism operators intended to make a living at the very start of their businesses. It also reflects that farmers still live a hard life in China.

\section{B. Dominant Start-up Goals}

There are something in common between Chinese and Australian dominant start-up goals. "Living in the right environment", "enjoy a good lifestyle", "to become financially independent", and "to meet interesting people" rank first, while "to support my leisure interests", "to keep my family together", "keep it as family property", "to provide a retirement income", and "to gain reputation by running businesses" rank last. This shows that China and Australian operators run farm hotels mainly to pursue beautiful natural environment, rural lifestyle, economic independence and social intercourse, but rarely care about satisfying interests and hobbies, keeping the family together, taking it as family property, earning retirement income and gaining reputation.

There are also something different between Chinese and Australian dominant start-up goals. "making more money" receives more recognition from rural tourism operators in three Chinese cities than those in Queensland of Australia, while "being one's own boss" shows the quite opposite tendency. This illustrates that Chinese rural tourism operators care more about economic goals at the start of their businesses, but they are shy to say "being one's own boss", while making money is not the main goal of Australian farm operators. Tourism operators in Queensland of Australia are explicit about the goal of "being one's own boss" because they think of "being one's own boss" as realizing their own value. According to the hierarchy of needs, their goal ranks relatively high.

\section{Formal Business Goals}

\section{A. Recessive Business Goals}

There are something in common between Chinese and Australian recessive formal business goals. "business reputation" ranks first. Then "business priority", "family priority" and "operation performances" rank successively. This illustrates that farm hotel operators in both countries cares the most about business reputation, while they care the least about business performances. In other words, rural tourism operators first consider "business reputation" in actual business process. But from the aspect of business performances, the operating income of rural tourism did not meet the their anticipation.

There are something different between Chinese and Australian recessive formal business goals. "Business priority" and "family priority" receive more recognition from rural 
tourism operators in three Chinese cities than in Queensland of Australia. But "business reputation" and "operation performances" are quite opposite. That shows Chinese operators care more about profit-making of "business" and "family" unity ,and care less about "business reputation" while running businesses than rural tourism operators in Queensland of Australia. At the same time, the operation performances of rural tourism operators in Queensland of Australia are better.

\section{B. Dominant Business Goals}

There are something in common between Chinese and Australian dominant formal business goals. "to present a good business image", "Delivery of high quality products and service is my top priority", "the business runs on high moral standards", "to keep business growing" and "to make profit", these dominant formal business goals rank in the first few places both in China and Australia. "it should be run on purely business principles", "to sell the business at the best possible price", "formal business goals are not necessary" and "at present the business meets my performance targets"- these few dominant formal business goals rank in the last few places both in countries.

This shows that rural tourism operators in two countries pay more attention to good business image, high moral standards, delivery of high quality products and service, making money and future business development and so on. They care less about business operation concept, produce and service price. In other words, they give more consideration to lifestyle and making more friends, and they are not willing to sell the farmhouse in the near future.

The differences in dominant formal business goals between Chinese and Australian farm hotel operators lie in the following aspects. Dominant formal business goals, such as "to keep business growing", "it should be run on purely business principles", "formal business goals are not necessary" and "my / my family's interest takes priority over business", obviously receive more recognition from rural tourism operators in Shanghai, Wuhan, and Chengdu in China than in Queensland of Australia. But "to make profit", "enjoying the job" is more important than "making a lot of money" and "at present the business meets my performance targets "receive less recognition from rural tourism operators in Shanghai, Wuhan, and Chengdu in China than in Queensland of Australia.

This means that rural tourism operators in Chinese three cities care more about business interests. This is possibly due to the consideration of easy management of small family business in China. Even if they have no formal business goals, they can operate the business smoothly. While rural tourism operators in Queensland of Australia care more about job involvement.

\section{Formal Business Goals}

The common points of family-related goals between Chinese and Australian farm hotel operators lie in the following aspects. "To prevent disharmony among family members", "share key decisions with the family members" and "to earn enough money to support the families" rank in the first few places, while "to train children to be future rural tourism operators", "to provide job opportunities for family members" and "to pass the business to their children or family members" rank in the last few places. It means that farm hotel operators in both countries pay more attention to family unity and harmony, sharing decision-making and earning money to make a living and so on, but they rarely focus their attention on the future development and inheritance of businesses , and they also care little about job opportunities.

The differences of family-related goals between Chinese and Australian farm hotel operators lie in the following aspects. "To enhance family position in society" "to ensure that family members have a lot of free time together" obviously receive more recognition from rural tourism operators in three Chinese cities than those in Queensland of Australia. This illustrates that rural tourism operators in China give more consideration to family social status enhancement as well as making money. In addition, they also want to share time together with family members by operating rural tourism.

\section{Underlying Causes of Farm Hotel Multi-goal Differences between China and Australia}

To some extent, the multi-goal differences of rural tourism operators in China reflect operation performances of Chinese farm hotel operators. A lot of deep social problems hidden behind it are worthy of further research.

\section{A. The Differences of Demographical Traits}

\section{1) The Differences of Urban and Rural Population Distribution}

In developed countries, people mainly live in urban areas, while rural population constitutes only a small proportion. Take France for example, its agricultural population accounts for only $2 \%$. As the economy develops, the rural population continues to decrease. To maintain traditional culture in the countryside and control the turnover of rural labors, governments encourage more people to stay in the countryside to ensure gradual and stable urbanization. Rural tourism is an important measure taken by governments all over the world to solve such problems. The situation in China is just the opposite. China now has a population of about1.3 billion, with nearly half in rural areas, which results in serious surplus of rural labor. So the purpose of Chinese government to develop rural tourism is to encourage more farmers leave rural areas.

\section{2) The Different Population Age Structure}

Most developed countries entered population aging stage. Due to good employment conditions, it is easy for young people to find jobs in cities. Meanwhile, per capita income in developed countries ranks high. For example, labour cost in the United States is 3.1, Japan 3.0, Chinese Hong Kong 2.9, South Africa 2.6, South Korea 2.2, but labour cost in China is as low as 1.0. So young and middle-aged people in developed countries do not want to stay in rural areas and very few people want to engage in farm hotel operations. Some developed areas in China have entered population aging stage, but the overall demographic dividend still remains. Although millions of farmers emigrate to towns and cities, quite a lot still stay in the rural areas due to competitive environments in 
cities. Some of them choose to run farm hotels and others choose to be employees. In China, most farmers engaging in rural tourism operation regard farm hotel operation as more efficient than traditional agricultural production.

\section{B. The Different Social System}

In China, urban and rural areas are not only geographical concepts, but also different social system and welfare. Because of the existence of long-term dualistic social structure, the segmentation of urban and rural areas come into being in China. Rural areas are artificially isolated from urban areas through a series of systems discriminating against peasants. Dualistic social systems include household registration, housing, food supply, the supply of subsidiary foodstuffs, education, health care, employment, insurance, labour and social security, marriage, military recruitment and so on. These become the bases of judging urban and rural residents. Because of the implementation of different systems in urban and rural areas, there are great differences in social welfare of urban and rural residents. In the last 30 years, in some developed areas, the urban-rural gap was significantly reduced or even eliminated. But the urban-rural dualistic structure which takes the place of household registration as a prerequisite does not disappear, and the urban-rural gap in some areas even has been institutionalized. Take conscription as an example, urban soldiers' employment can be arranged, but rural soldiers rarely can. Another example is social security, which urban residents can enjoy, but the majority of rural residents can not. Nowadays, China's social security is still not perfect, especially in rural areas, social security is in great shortage. Rural residents live very hard lives. The pressure of social system is naturally reflected in the business motivations of rural tourism operators.

In Australia, a high-welfare society is established, and there are not so many traditional farmers as in China. They should be called proprietors of the agriculture and agro-food industry. They can enjoy the same health insurance, pension insurance and some other kinds of social welfare as other industry operators. They can retire at the age of 60 and are entitled to the minimum wage .

\section{The differences of culture}

\section{1) The differences of social culture}

Chinese culture is family-oriented, which pays attention to the duties and obligations of individuals. The traditional views of the Chinese people advocate "four Generations live under one roof" and "family reunion". In ancient times, there is an old saying that "if parents are still alive one can not travel to distant areas" (Shoufu Li 2008). In China, rural tourism operators' family decision making and family interests are relatively higher in operating activities. Some rural tourism operations take family as operation unit. Meanwhile, the Chinese culture lays more emphasis on personal and family honour. They want to pursuit family values and honours, bring prestige and honour to their families and clans, gloriously go home after having won high honours and social recognition and so on what Chinese are all proud of Chinese people have a strong sense of hierarchy. The family structure is more complex. Most traditional happy families are four generations under one roof. It is showed as follows: In China, rural tourism operators prefer to improve his and his family's reputation, recognition and his own status in his own family in society when it opened for business.

Western culture is characterized by "individualism". It emphasizes individuals' freedoms and rights. Western "individualism" mainly lays emphasis on individual freedom, individual rights, and personal independence. It lacks the sense of responsibility and duty to family. In western culture, the rise of "individualism" leads to the result that family and clan ties are relative loose. Westerners have a strong sense of equality. Family structure is simple. Parents and minor children make up nuclear family. Since it is self-centred, it is impossible to take some members of the family as the centre, such as parents. So they do not have a strong sense of filial respect to their parents. It is showed as follows: in Queensland of Australia, rural tourism operators prefer to be their own boss and to pursue a kind of a lifestyle, when it opened for business.

Hofstede (1980) studied the relationship between the individuals and the whole society that they compose. In order to allow some kind of culture to survive, everyone must put the weights of "consider oneself" and "consider others" on the communication scale to regulate. "Collectivism" emphasizes common interests, abiding custom, unity and cooperation, and mutual dependence. "Individualism" is an attitude of making a difference between groups and individuals. Everyone should be responsible for their own goals and behaviour. It can be seen that these two cultural factors can encourage certain groups of people to become maverick, or to comply with the authority. During the 53 countries chosen around the world, Western countries such as the United States, Australia, Britain and Canada and so on are placing on the most popular "individualism" ranking list. While oriental countries such as China, Malaysia, Singapore and Indonesia and so on are typical "collectivism" value orientation.

\section{2) The Differences of Lifestyle}

Different climatic conditions and geographical environment caused many differences in lifestyles between China and the West. Such as the United States, Canada, and Australia, these countries are sparsely populated. Residents are in favour of quiet, and they do not like living in groups. China's population is concentrated. Chinese like liveliness. It can meet the social needs. This is also reflected in the rural tourism operators: rural tourism operators want to take the measures of intensification and scale. By this means they can achieve scale economy of its operation. At the same time, rural tourists are accustomed to this way. But the scale of rural tourism operation in Western countries is relatively small. They take the pattern of family and miniaturization.

The differences of Lifestyle are also reflected in eating. Westerners do not pay attention to eating, the form and flavour of the dishes. First, they pay attention to the nutrition and then flavour. Chinese pay too much attention to the form and flavour of the dishes. First, they pay attention to the colour, smell and taste, and then to the nutrition. Chinese People regard food as their prime want. They give the first and highest place to eating. Chinese rural tourism operators lay more emphasis on the development and operation of the "eating", 
while western rural tourism operators pay little attention to eating, even many of them do not provide food.

\section{$D$. The differences of understanding of rural areas}

\section{1) The Differences of Understanding of Rural Areas}

between China and Western Countries

Many Chinese think that rural areas are countryside. They ignore their differences. In fact, there are obvious differences between them. The countryside is a broad area and sparsely populated. The residents there have a common way of life and relationship. Agricultural production is the main industry there. It can not accommodate other kinds of industries. Nonagriculture-based industry is excluded from this area. So countryside is a kind of rural area. Rural areas can accommodate agriculture as well as various non-agricultural industries. This is because the concept of "countryside" is static, but the concept of "rural area" is dynamic (Jiegang Wang, 2001). Developed rural areas can carry tertiary industries, but backward countryside can not carry other types of industries.

\section{2) The differences of understanding of rural tourism between Chinese and western rural tourism operators}

In different countries and at different stages of development, tourism carries different functions. In developing countries, tourism is an industry function. It is a means to promote national economic development. In developed countries, tourism's main function is service. Tourism operator is a means to meet the tourism leisure needs of residents. Because of tourism's different functions, it inevitably results in a different understanding of the operational behaviour. In China, rural tourism operators regard it as a type of tourism product. Due to their poor living conditions, they regard it as an alternative livelihood of agriculture. In western countries, rural tourism operators regard it as a rural lifestyle. It is not a means of livelihood. It is just another way of life.

\section{Conclusions}

Chinese and Western rural tourism operators both pay attention to "Social intercourse" and "lifestyle" in their startup goals. They consider the least for the goal of self-reliance. Rural tourism operators in the three areas in China give more recognition to the goal of "money". Chinese and Western rural tourism operators both pay attention to "living in a favourite rural environment", "enjoy a favourite way of life", "economic independence", and "get to know more interesting people". They pay least attention to "satisfy interests and hobbies", "let the family together", "take it as family property", "take it as pension", and "improve their reputation and visibility". "Making more money" receives more recognition from rural tourism operators in China. This illustrates that rural tourism operators' main start-up motive is economic, but they are ashamed to speak out the goal of "being one's own boss".

In the aspect of formal business goals, Chinese and Western rural tourism operators first consider "business reputation". They rarely take business priority" and "family priority" into consideration. Their operating results are both poor. "Business priority" and "family priority" receive more recognition from rural tourism operators in China, but "business reputation" and "operating results" receive less recognition. China and western rural tourism operators both consider the following formal business goals "to establish a good image of rural tourism", "to provide high quality products and service is my top priority", "to operate rural tourism with high moral standards", to make rural tourism develop and grow" and "to make profit". They pay little attention to "to operate rural tourism based solely on the business concept", "to sell rural tourism at the best price", "formal business goals are not necessary". Rural tourism operators in China give more consideration to "business acumen" and "family and one self"s interests", While rural tourism operators in Queensland in Australia pay more attention to "they can engage in the work" and "they can make profit". So they can achieve their anticipated goal more easily.

In the aspect of family-related goals, the Chinese and Western rural tourism operators consider more about "to avoid discord among family members", "the common solution of the main problems" and "to earn enough money to feed the families". They seldom consider the following goals-"to train children to be rural tourism operators", "to provide employment opportunities for family members" and "to pass rural tourism on to their children or family members". Rural tourism operators in China give more consideration to "to enhance family's and one self"s social status as well as "to make money to get rich". In addition, they want to unite family members and share the affectionate time that they work and live together by operating rural tourism.

Finally, this study suggests that the differences of Chinese and Western rural tourism operators' multi-goal are mainly due to population characteristics, social systems, and economical development level of rural tourism operators.

\section{Acknowledgment}

This research was financially supported by "Education Training of New Professional Farmers Based on Action Mechanism of Rural Tourism on Farmers' Competences in Tourist Destination Community" (Funded by the Education Department of Henan Province Grant No. : ZJA14102); "Education Training of New Agricultural Management Subject Leaders in Henan Province" (Funded by the Education Department of Henan Province Grant No. : ZJA14001); "Education Training of New Professional Farmers in Henan Province" (Funded by the Education Department of Henan Province Grant No. : ZJA14101). "Agritainment Development in the periphery of Zhengzhou City", the Fundamental Research Funds from the Science and technology Bureau of Zhengzhou City (Grant NO. 121PPTGG464).

\section{References}

[1] Wenchang Sun, Modern Tourism Development, Qingdao: Qingdao Press, 2001, pp.226.

[2] Guihua Yang, Xiuhong Wang, Rural Tourism Management Manual. Beijing: China Tourism Press, 2006, pp.1-32.

[3] Oppermann. M, "Rural Tourism in Southern Germany", Annals of Tourism Research,vol.23,no.1,pp,86-102,1996

[4] Jun Wen, Meicai Wei, "Discussion about Rural Tourism Development Mode", Ecological Economy,Vol,6,pp.125-127, 2002

[5] Donald Getz, Jack Carlsen, "Characteristics and goals of family and owner-operated businesses in the rural tourism and hospitality sectors ",Tourism Management, vol.21,pp.547-560,2000 